\title{
Interrelationship Among School Characteristics, Parental Involvement, And Children's Characteristics In Predicting Children's Victimization By Peers: Comparison Between The United States And Three Eastern Asia Countries
}

Gang Lee, Ph.D., Kennesaw State University, USA

Yanghee Kim, Ph.D., Kennesaw State University, USA

\begin{abstract}
To identify ways that national culture, school characteristics, and individual attributes impact the victimization of students in Grade 8, data from the United States and three East Asian countries (i.e., Japan, S. Korea, and Taiwan) were compared using the 2011 Trends in International Mathematics and Science Study (TIMSS) and Hierarchical Liner Modeling (HLM). The school-level factors measured by school size, school resources, and perceived behavioral problems on campus did not predict middle school students' victimization in the United States, but significant positive parental involvement and negative school resources were found to impact the victimization of students in the East Asian countries. Regarding the effects of the student-level variables, boys, in comparison to girls and students showing less attachment to the schools, were more victimized in U.S. and East Asian schools. Individual students' perceived parental monitoring was a significant and positive predictor of students' victimization in the East Asian schools only. The standard test scores in mathematics were not predictive of victimization in U.S. and East Asian participants. The results indicated that understanding the ecological factors involved in victimization is important to intervene effectively, protect students, and prevent peer victimization on campus.
\end{abstract}

Keywords: School Characteristic; Parental Involvement; Children's Characteristics; Korea, Japan, Taiwan, U.S.A

\section{INTRODUCTION}

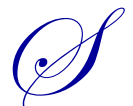

tudent victimization in the school setting is ongoing and increasing in the United States and other countries (Malete, 2007; Nansel et al., 2001; Smith, 2003). About 30\% to 60\% experience victimization, and 6\% to $10 \%$ of student's experience repeated victimization during a semester or a school year (Card \& Hodges, 2008). Victimized children show internalizing symptoms such as depression, loneliness, anxiety, and low self-esteem, and externalizing symptoms such as hyperactivity, impulsiveness, and aggression. It is important to study the risk and protective factors associated with victimization to protect children from being bullied at school and maximize their academic potential (Nakamoto \& Schwarts, 2009).

Students are more victimized because they do not have favorable individual characteristics that make them less prone to victimization (Card \& Hodges, 2008); they have less involved parents who do not much pay attention to changes in their children's behaviors (Antonopoulou, Koutrouba, \& Bablis, 2011; Card \& Hodges, 2008; Lee \& Song, 2012); they are taught in negative school climates that do not actively monitor students' behaviors (Card \& Hodges, 2008); and there is a less favorable culture shown by several countries in Asia to academic variances (see Nakamoto \& Schwarts, 2009). 
Card and Hodges (2008) concluded that "there is sufficient research supporting the existence of several personal, academic, and interpersonal correlates of victimization, and further replication of these findings adds little to our knowledge" (p. 458). However, future researchers should strive to identify the mediators that can reduce the magnitude of the relationships between and among personal, academic, and interpersonal correlates and peer victimization (Card \& Hodges, 2008; Nakamoto \& Schwarts, 2009). It is important to study the impact of mediators that are specific to different school contexts and unique cultural settings (Card \& Hodges, 2008). Such studies are important not only in shedding light on selecting intervention strategies that can reduce peer victimization specific to given school and cultural contexts effectively but also in guiding schools and nations in allocating limited funds to evidence-based strategies.

Using the 2011 Trends in International Mathematics and Science Study (TIMSS), we investigated (a) how school characteristics measured by school size, school resources, perceived behavioral problems on campus, and parental involvedness in school can predict peer victimization on campus; (b) how the individual-level measurement of parental monitoring at home can predict peer victimization; (c) how children's individual differences, such as gender, academic achievement, and school attachment, can predict peer victimization; and (d) how interrelationships among school characteristics, parental monitoring, and children's characteristics in predicting peer victimization are different when compared between the United States and three countries in East Asia, namely, Japan, Korea, and Taiwan.

\section{LITERATURE REVIEW}

In terms of discussing ways that school contexts influence peer victimization on campus, schools in which students are enrolled are considered a vital component of children's development because school type, along with the relative prosocial nature of the school climate, can create a school environment that might affect students' delinquent behaviors (Lee \& Song, 2012). Therefore, the problem behaviors of students as perceived by school officials have been linked to student victimization, including physical injury and the feeling of being unsafe at school. Lack of school resources also has been associated with student victimization (Welsh, 2000). Because peer victimization in the school setting can occur in hallways, playgrounds, lunchrooms, parking lots, and behind buildings (Card \& Hodges, 2008), it is worth considering school size a risk factor in predicting peer victimization.

It has been reported that parenting behaviors of support, involvement, and responsiveness are related to lesser victimization (Card \& Hodges, 2008). Parental monitoring of their children at home is an important factor that can reduce the students' problem behaviors and victimization in schools (Antonopoulou et al., 2011). However, Georgiou (2008) found that mothers' monitoring of children's non-academic lives, involvement in schooling, and assistance with homework were not predictors of the victimization of Greek children in Grades 4 to 6 but that mothers' anxious, overprotecting behavior did predict the children's victimization.

In studying the impact of children's individual differences in peer victimization, it has been reported that adolescent boys experience more victimization in schools than adolescent girls do (Lai, Ye, \& Chang, 2008); children who show less academic achievement experience more victimization than peers (Nakamoto \& Schwarts, 2009); children who express less favorable feelings toward school experience more victimization from peers; students' bonding, as measured by attachment to school and beliefs about and commitment to school, mediates the relationship between school characteristics and students' behavioral problems in school (Lai et al., 2008).

In addition to studying variances in school, parental, and individual characteristics, we also were interested in inquiring about ways that national culture, a relatively distant system compared to individual, family, and school (Bronfenbrenner, 1986), mediates children's victimization. Cultural factors contribute to shaping parenting and parental involvement behaviors (Costigan \& Koryzma, 2011). Nakamoto and Schwarts's (2009) meta-analysis of the relationship between the academic achievement of children from elementary school to high school and peer victimization showed that the culture in which children live influences the magnitude of the relationship. A stronger negative relationship between academic achievement and peer victimization has been found in Asia when compared to Europe. However, the magnitude of the negative relationship was not different based upon a comparison between Asia and the United States (Nakamoto \& Schwarts, 2009). 
We chose Japan, S. Korea, Taiwan, and the United States to study the impact of culture on peer victimization because the economic standings (Indexmundi, 2016; World Bank, 2016) and educational systems (see Table 1) of these countries are similar, and all of them have invested significantly in industries for the future that need workers trained to use mathematical and analytical skills (Manyika et al., 2012). Even though all of the countries selected for this study recognize the importance of math education in expanding their economies, it has been reported that the three East Asian countries place more value in math in their curricula than the United States does (Peterson, Woessmann, Hanushek, \& Lastra-Anadón, 2011). Therefore, given the higher expectation of math performance in the three East Asian countries, children who demonstrate high math performance in these countries might be less victimized by bullying. Identifying ways to shift the current school culture in the United States to value higher performance in math can be an important policy implication.

Table 1. School Systems in Taiwan, Japan, Korea and U.S.

\begin{tabular}{|c|c|c|c|c|}
\hline & Taiwan $^{\mathbf{a}}$ & Japan $^{\text {b }}$ & Korea $^{\mathbf{c}}$ & U.S. ${ }^{d}$ \\
\hline Pre-K/Kindergarten & 2-6 yrs old & $3-6$ yrs old & $3-6$ yrs old & $2-5$ yrs old \\
\hline \multirow{3}{*}{ Elementary } & $7-12$ yrs old & $7-12$ yrs old & $7-12$ yrs old & 6-11 yrs old \\
\hline & 1-6th grades & 1-6th grades & 1-6th grades & $1-5$ th grades \\
\hline & Compulsory & Compulsory & Compulsory & Compulsory \\
\hline \multirow{3}{*}{ Middle School } & $13-15$ yrs old & $13-15$ yrs old & $13-15$ yrs old & $12-14$ yrs old \\
\hline & 7-9th grades & 7-9th grades & 7-9th grades & 6-8th grades \\
\hline & Compulsory & Compulsory & Compulsory & Compulsory \\
\hline \multirow{3}{*}{ High School } & $16-18$ yrs old & $16-18$ yrs old & $16-18$ yrs old & $15-18$ yrs old \\
\hline & 10-12th grade & 10-12th grade & $10-12$ th grade & $9-12$ th grade \\
\hline & Optional & Optional & Optional & Compulsory \\
\hline
\end{tabular}

${ }^{a}$ Taiwanese Ministry of Education (2015)

${ }^{\mathrm{b}}$ Japanese Ministry of Education, Culture, Sports, Science and Technology (2015)

${ }^{c}$ Korean Ministry of Education (2015)

${ }^{\mathrm{d}}$ National Center for Education Statistics, Institute of Education Sciences (2015)

Certain school characteristics, parental behaviors, and children's individual characteristics impact peer victimization. What remains unknown is how these factors interact in predicting peer victimization. In terms of how to reduce bullying victimization in the school setting, we asked which approach is better in which cultural context: (a) Are intervening school characteristics, such as reducing school size, lowering the frequency of problem behaviors on campus, increasing parental involvement in school, and/or securing budgets for instructional materials better, or (b) are paying attention to individual characteristics of students, such as gender of children, students' monitoring by parents, students' achievement in math, and/or student attachment to the school, better in reducing student victimization on campus?

\section{METHODS}

\section{Data}

The data source for this study was the 2011 TIMSS, developed by the International Association for the Evaluation of Educational Achievement (IEA). The TIMSS data were collected from students in Grades 4 and 8, along with their teachers and schools, in 63 countries to measure trends in mathematics and science achievement and to observe curricular implementation and instructional practices (Foy, Arora, \& Stanco, 2013). In this study, Grade 8 students whose peer victimization was relatively higher than that of students in Grade 8 were included (DeVoe et al., 2004). A total of 14,622 Grade 8 students in 438 middle schools from Japan, S. Korea, and Taiwan were chosen as the East Asian participants (4,414 Grade 8 students in 138 middle schools from Japan, 5,166 in 150 middle schools in South Korea, and 5,042 in 150 middle schools from Taiwan). The U.S. participants were 10,477 Grade 8 in 501 middle schools. 


\section{Measures}

\section{Dependent Variable - Peer Victimization}

Peer victimization was measured by asking the following question: During this year, how often have any of the following things happened to you at school? (a) I was made fun of or called names, (b) I was left out of games or activities by other students, (c) Someone spread lies about me, (d) Something was stolen from me, (e) I was hit or hurt by another student, and (f) I was made to do things I didn't want to do by other students. For each item, four response options were derived: 1 =never, 2 = a few times a year, $3=$ once or twice a month, and $4=$ at least once a week.

\section{Independent Variables}

Independent variables (IVs) that could impact the dependent variable (DV) of peer victimization were selected from two levels: individual and school. Individual student IVs included gender, degree of parental monitoring, school attachment, and academic performance. School IVs were size of school, parental involvement in school, school resources, and perceived students' behavioral problems reported by school officers.

\section{Student-Level IVS}

\section{$\underline{\text { Gender of Students }}$}

Students' gender was coded as $0=$ boy and $1=$ girl.

$\underline{\text { Parental Monitoring }}$

Students were asked about their perceptions of parental monitoring with four items: (a) My parents ask me what I am learning in school, (b) I talk about my schoolwork with my parents, (c) My parents make sure that I set aside time for my homework, and (d) My parents check if I do my homework. The responses were coded as $1=$ never or almost never, 2 = once or twice a month, 3 = once or twice a week, and $4=$ every day or almost every day.

\section{School Attachment}

Students were asked the following: How much do you agree with the following statements about your school?: (a) I like being in school, (b) I feel safe when I am at school, and (c) I feel like I belong at this school. For each item, four response options were given: $1=$ disagree a lot, $2=$ disagree a little, $3=$ agree a little, and $4=$ agree a lot.

\section{$\underline{\text { Academic Performance }}$}

Academic performance was measured by a standardized mathematics score. In the 2011 TIMSS, five plausible values were calculated as the best estimates of student's mathematics performance. For this study, the first plausible value was used as students' academic performance (see Foy et al., 2013).

School-Level IVS

\section{$\underline{\text { Size of School }}$}

The total number of students who were enrolled was used as the size of school.

Parental Involvement in School

The middle school principals were asked the following: How often does your school ask parents to do the following?: (a) Volunteer for school projects, programs, and trips, and (b) serve on school committee. The response choices were $1=$ never, 2 once a year, $3=2$ or 3 times a year, and $4=$ more than 3 times a year. 


\section{$\underline{\text { School Resources }}$}

School resources were measured by asking the middle school principals the following: How much is your school's capacity to provide instruction affected by a shortage or inadequacy of the following?: (a) instructional materials, (b) supplies, (c) school buildings and grounds, (d) heating/cooling and lighting systems, (e) instructional space, and (f) technologically competent staff. The response options were $1=$ not at all, $2=$ a little,

$3=$ some, and $4=a$ lot .

\section{$\underline{\text { Perceived Behavioral Problems }}$}

Principals were asked to answer the following: On what degree is each of the following problems among eighth-grade students in your school?: (a) arriving at school, (b) absenteeism, (c) classroom disturbance, (d) cheating, (e) profanity, (f) vandalism, (g) theft, (h) intimidation of verbal abuse among students, and (9) physical injury to other students. The response options were $1=$ not a problem, $2=$ minor problem, $3=$ moderate problem, and $4=$ serious problem .

\section{Data Analyses}

We first examined the relationships among student-level IVs, including victimization, using a correlation for the United States and East Asia. The correlations among the school-level IVs were presented to show how the school characteristics were related each other in the United States and East Asia. The goal of the study is to determine which student-level and school-level factors influenced students' victimization in the United States and East Asian countries. To achieve this goal, finally, we used HLM to estimate the relationships between the individual and school IVs simultaneously (Raudenbush \& Bryk, 2002). The HLM 6.6 program was used to effectively estimate the effect of school level factors and student level attributes on students' victimization in school.

\section{RESULTS}

Table 2 shows the correlations, means, and standard deviations of the student-level IVs for the U.S. and East Asian schools. Although the mean of peer victimization score was a little higher in the United States, the pattern of the correlation for the student-level IVs was similar, except for the correlations between parental monitoring and victimization. Student victimization was significantly associated with other student characteristic IVs. Girls were less likely to be victimized at the middle school level $(r=-.049, p<.01$ for the United States; $r=-.228, p<.01$ for the East Asian countries). Higher school attachment and academic performance were associated with a lower level of victimization $(r=-.284, p<.01 ; r=-.030, p<.01$ for the United States; $r=-.198, p<.01 ; r=-.030, p<.01$ for the East Asian countries). However, the victimization score was positively and significantly related with the parental monitoring measure in the East Asian countries $(r=.022, p<.01)$; a negative relation was found in the United States $(r=-.087, p<.01)$.

Table 2. Means, Standard Deviations, and Correlations of Student-Level Variables

\begin{tabular}{|c|c|c|c|c|c|c|c|}
\hline \multicolumn{8}{|l|}{ U.S. } \\
\hline & 1 & 2 & 3 & 4 & Mean & S.D. & $\mathbf{N}$ \\
\hline 1. Peer victimization & 1.000 & & & & 9.398 & 3.513 & 10178 \\
\hline 2. Gender $(1=$ girl $)$ & $-.049^{* *}$ & 1.000 & & & .505 & .500 & 10439 \\
\hline 3. Parental monitoring & $-.087^{* *}$ & $-.024^{*}$ & 1.000 & & 11.755 & 3.398 & 10314 \\
\hline 4. School attachments & $-.284^{* *}$ & $.051^{* *}$ & $.306^{* *}$ & 1.000 & 9.079 & 2.268 & 10309 \\
\hline 5. Academic Performances & $-.060^{* *}$ & -.015 & $.020^{*}$ & $.200^{* *}$ & 508.919 & 76.112 & 10477 \\
\hline \multicolumn{8}{|c|}{ East Asian Countries (Japan, Korea, Taiwan) } \\
\hline & 1 & 2 & 3 & 4 & Mean & S.D. & $\mathbf{N}$ \\
\hline 1. Peer victimization & 1.000 & & & & 9.087 & 3.239 & 14463 \\
\hline 2. Gender (1=girl $)$ & $-.228^{* *}$ & 1.000 & & & .500 & 0.500 & 14571 \\
\hline 3. Parental monitoring & $.022^{* *}$ & $-.019^{*}$ & 1.000 & & 9.347 & 3.395 & 14530 \\
\hline 4. School attachments & $-.198^{* *}$ & $.049^{* *}$ & $.214^{* *}$ & 1.000 & 8.799 & 1.950 & 14520 \\
\hline 5. Academic Performances & $-.030^{* *}$ & -.003 & $.195^{* *}$ & $.156^{* *}$ & 599.719 & 95.254 & 14622 \\
\hline
\end{tabular}


The school-level IVs were not strongly associated with each other in general (see Table 3). In the United States, school size was negatively associated with the number of school resources $(r=-.119, p<.05)$, but it was negatively related to perceived behavioral problems in the East Asian schools $(r=-.169, p<.01)$. The perceived behavioral problems were positively associated with the number of school resources in the U.S. $(r=.250, p<.01)$ and East Asian $(r=.131$, $p<.01)$ schools.

Table 3. Means, Standard Deviations, and Correlations of School-Level Variables

\begin{tabular}{|c|c|c|c|c|c|c|}
\hline \multicolumn{7}{|l|}{ U.S. } \\
\hline & 1 & 2 & 3 & Mean & S.D. & $\mathbf{N}$ \\
\hline 1. Size of school & 1.000 & & & 730.860 & 346.816 & 454 \\
\hline 2. Parental involvement & .031 & 1.000 & & 6.389 & 1.482 & 440 \\
\hline 3. School resources & $-.119^{*}$ & .045 & 1.000 & 9.960 & 4.189 & 428 \\
\hline 4. Behavioral problems & .072 & .001 & $.250^{* *}$ & 19.294 & 4.743 & 425 \\
\hline \multicolumn{7}{|c|}{ East Asian Countries (Japan, Korea, Taiwan) } \\
\hline & 1 & 2 & 3 & Mean & S.D. & $\mathbf{N}$ \\
\hline 1. Size of school & 1.000 & & & 1093.820 & 859.505 & 435 \\
\hline 2. Parental involvement & -.017 & 1.000 & & 6.254 & 1.555 & 429 \\
\hline 3. School resources & .070 & .000 & 1.000 & 10.308 & 4.310 & 425 \\
\hline 4. Behavioral problems & $-.169^{* *}$ & -.038 & $.131^{* *}$ & 18.460 & 7.552 & 417 \\
\hline
\end{tabular}

For the U.S. middle schools, the average victimization was 9.396, and 3.0\% of total variation in victimization was between U.S. middle schools (intraclass correlation $r h o=.030$ ). The average victimization mean for the East Asian schools was 9.091 (see Table 4, Unconditional model, fixed effect for the East Asian schools), and 7.2\% of total variation in victimization was between the East Asian middle schools (intraclass correlation rho $=.072$ ). Unconditional models of student victimization showed that the U.S. middle schools had a higher level of school victimization than the East Asian middle schools and the East Asian schools had more variation in the occurrence of victimization than ones in the U. S. schools.

Table 4. Unconditional Models of Student-Level and School-level Variables with Student Victimization for the U.S. and East Asia (Japan, South Korea, Taiwan).

\begin{tabular}{|c|c|c|c|c|c|c|}
\hline \multicolumn{7}{|l|}{ U.S. } \\
\hline Fixed Effect & B & SE & T-ratio & DF & P-vaule & \\
\hline INTRCPT & 9.396 & .049 & 193.579 & 404 & .000 & \\
\hline Random Effect & S.D & $\mathbf{S}^{2}$ & $\mathrm{Chi}^{2}$ & DF & P-vaule & rho \\
\hline School & .601 & .361 & 660.687 & 404 & .000 & .030 \\
\hline Student & 3.407 & 11.607 & & & & \\
\hline \multicolumn{7}{|c|}{ Intraclass Correlation rho $=.361 /(.361+11.607)=.030$} \\
\hline \multicolumn{7}{|c|}{ East Asia } \\
\hline Fixed Effect & B & SE & T-ratio & DF & P-vaule & \\
\hline INTRCPT & 9.091 & .051 & 177.824 & 402 & .000 & \\
\hline Random Effect & S.D & $\mathbf{S}^{2}$ & $\mathrm{Chi}^{2}$ & DF & P-vaule & rho \\
\hline School & .087 & .754 & 1439.761 & 402 & .000 & .072 \\
\hline Student & 3.120 & 9.733 & & & & \\
\hline
\end{tabular}

Table 5 shows the results of multilevel modeling using both student-level and school-level IVs to examine students' victimization in the United States and the three East Asian countries. Using HLM, four school-level IVs and four student-level IVs were included in the full random intercept model. In the United States, the school-level factors did not predict middle school students' victimization, but in the East Asian countries, school-level IVs of parental involvement and school resource did significantly influence students' victimization $(B=.055, p<.05$, and $B=.021$, $p<.05$, respectively).

For the effects of the student-level IVs, girls were less likely than boys to be victimized both in the U.S. ( $B=-.174, p$ $<.05)$ and the East Asian $(B=-1.270, p<.01)$ schools. Individual students' perceived parental monitoring was a significant and positive predictor of students' victimization $(B=.063, p<.01)$ in the East Asian schools only, the 
same as in the previous bivariate correlation analysis. School attachment was significantly and negatively associated with students' victimization in the U.S. $(B=-.412, p<.01)$ and the East Asian $(B=-.329, p<.01)$ schools. The standard test scores of mathematics as a measure of academic performance was not a predictive factor of victimization in the U.S. and the East Asian schools.

Table 5. Full Random Intercept Models of Student-Level and School-level Variables with Student Victimization for the U.S. and East Asian Countries (Japan, South Korea, Taiwan).

\begin{tabular}{|c|c|c|c|c|c|c|}
\hline \multirow[b]{2}{*}{ Fixed Effect } & \multicolumn{3}{|c|}{ U.S. } & \multicolumn{3}{|c|}{ East Asia } \\
\hline & B & & SE & B & & SE \\
\hline \multicolumn{7}{|l|}{ School Level } \\
\hline Intercept & 9.392 & & $.045^{* *}$ & 9.088 & & $.011^{* *}$ \\
\hline Size of School & -.000 & & .000 & -.000 & & .000 \\
\hline Parent Involvement & .027 & & .030 & .055 & & $.027^{*}$ \\
\hline School Resource & -.013 & & .011 & .021 & & $.010^{*}$ \\
\hline Problem Behavior & -.006 & & .010 & .008 & & .006 \\
\hline \multicolumn{7}{|l|}{ Student Level } \\
\hline Gender (1=girl) & -.174 & & $.081^{*}$ & -1.270 & & $.060^{* *}$ \\
\hline Parent Monitoring & .002 & & .013 & .063 & & $.008^{* *}$ \\
\hline School Attachment & -.412 & & $.023^{* *}$ & -.329 & & $.017^{* *}$ \\
\hline Academic Performances & -.000 & & .000 & .000 & & .000 \\
\hline Random Effect & S.D. & $\mathrm{S}^{2}$ & DF & S.D. & $\mathrm{S}^{2}$ & DF \\
\hline School & .528 & $.279^{* *}$ & 400 & .707 & $.501^{* *}$ & 398 \\
\hline Individual & 3.291 & 10.832 & & 3.008 & 9.052 & \\
\hline
\end{tabular}

$* P<.05 ; * * \mathrm{P}<.01$

\section{DISCUSSION}

This study inquired about the impact of individual, home, school, and country variances in predicting children's victimization. Specifically, we chose to study the following: Are children more prone to being victimized by bullying because of (a) their enrollment in schools with more perceived behavioral problems and a less productive learning environment caused by the lack of resources, (b) degree of parental involvement at home and/or in school, (d) their individual characteristics, and (d) culture where different levels of academic pressure exist and the behavioral norms of peer groups might be different?

In the United States, the school-level IVs did not predict middle school students' victimization. In the East Asian countries, on the contrary, the school-level IV of school resources did significantly influence students' victimization. When personnel in the East Asian countries perceived that the capacity of their schools to provide instruction was affected by a shortage of or inadequacy in the number of instructional materials, supplies, school buildings, and grounds; heating/cooling and lighting systems; instructional space; and technologically competent staff, they also reported that more students' were prone to bullying victimization on campus. In the East Asian countries, compared to the United States, support for seamless instruction seemed to be more important to reduce peer victimization on campus.

In terms of considering students' personal IVs in reducing peer victimization, the study results from the United States were somewhat comparable to those from the East Asian countries. Lai et al. (2008) also found that boys and students who reported less attachment (e.g., feeling safe or belonging) to their schools reported more peer victimization. Administrators and teachers in middle schools need to more pay attention to and monitor the behaviors of boys and ways to build a strong sense of community as a whole school. Schools with a strong sense of community that can be measured by children's attachment and trust to school are more likely to have lower rates of school violence and bullying victimization (Lai et al., 2008).

One interesting finding from this study is that parental involvement in school and parental monitoring at home did not predict the children's peer victimization in the United States but did in the East Asian countries. Instead of minimizing the peer victimization of their children, more parental involvement at home and in school predicted more peer victimization. These results were somewhat contradictory to other studies in the United States and Greece. In the 
United States, it was found that parents who did not pay much attention to changes in their children's behaviors at home could have contributed to their children's peer victimization (Antonopoulou et al., 2011; Card \& Hodges, 2008). Georgiou (2008) reported that Greek mothers' monitoring of their children's non-academic lives, assistance with homework, and involvement in schooling did not predict the peer victimization of their children in Grades 4 to 6. On the other hand, studies in other Western countries have shown that mothers' overanxious and overprotecting behaviors can be related to their children's peer victimization (Card \& Hodges, 2008; Georgiou, 2008).

In Asian countries, particularly Korea and China (Lee, Turnbull, \& Zan, 2009), parents exert unbelievable pressure on their children to succeed academically because acceptance at prestigious universities is considered a gauge of their children's life success (Huang, Hong, \& Espelage, 2013). Questions that the 2011 TIMSS asked related to students' perceptions of their parents' involvement at home centered on whether parents were concerned about their school learning and homework. Therefore, under consideration of the cultural contexts of the East Asian countries, which emphasize earning good grades, parents whose children reported more parental involvement at home might be overanxious in monitoring their children's school learning and homework. These parents might not value social interactions with peers at school, and their children might feel academic pressure and anxiety (Lee et al., 2009), making them susceptible to bullying victimization. Lee and Song (2012), who conducted their study in Korea, also found that parental involvement, as measured by the frequency of parents' conversations with their children's teachers and peers, positively predicted children's bullying behaviors. The researchers concluded that the parents of children who manifest bullying behaviors probably had to contact their children's teachers and peers more frequently.

The result of this current study reporting that standardized mathematic test scores did not predict the bullying victimization in middle schools in the United States and the East Asian countries were different from those of Nakamoto and Schwarts (2009), who found a negative relationship between standardized test scores and children's victimization in school. The different results might have been because academic achievement might not be a risk factor in predicting peer victimization. Poor academic achievement might be a consequence, not a predictor, of peer victimization (Card \& Hodges, 2008). This current study did not support the argument that cultural contexts in certain East Asian countries expecting children to achieve at academically high levels might explain the relationship between academic achievement and peer victimization (Nakamoto \& Schwarts, 2009).

In paying attention to the cultural impact of peer victimization, this current study found that when nationally representative schools are investigated, the rates of adolescent peer victimization seem similar, regardless whether a country adopts individualism, as in the United States, or collectivism, as in most countries in Asia. This finding is contrary to a review suggesting that peer victimization seems to be less frequent in areas where collectivism is valued (Huang et al., 2012) when other factors such as school resources, parental involvement, and children's attachment to school are considered simultaneously. In addition, this study showed that rather than children's academic achievement itself, parents' anxious behaviors at home concerning children's school learning and homework that are manifested by widely accepted cultural norms in the countries might impact on children's peer victimizations. In many Asian countries, parents' focus on their children's academic success has been perceived as "a survival response" (Huang et al., 2012, p. 887). More relaxed parenting might have a critical role in minimizing peer victimization in Asian countries.

Providing a comprehensive approach that includes interventions for all stakeholders, such as individual children who are victimized by bullies, peers involved in children's victimization, parents of victimized children, and teachers with whom victimized children interact, is the best way to reduce peer victimization (Huang, et al., 2013). However, if such a comprehensive intervention approach is not feasible because of budget issues, consideration must be given selectively to some of those risk and protective factors.

In the United States and East Asian countries, it is important to design effective intervention and prevention programs that target boys and support the building of school communities. When the goal is to reduce peer victimization on campus, it makes sense that schools need to pay more attention to programs that bring affectively different experiences to children. In addition, in the East Asian countries, it is critical to develop intervention programs that raise parents' awareness of the relationship between their overly anxious and concerned behaviors related to school learning and homework and the possibility of their children becoming the victims of peer bullying at school. In addition, to reduce 
peer victimization on campus, schools in the East Asian countries need to support various resources for teachers' uninterrupted instructions.

Results showed that in the East Asian countries, multiple levels of contexts influenced peer victimization experiences. Understanding the ecological factors involved in bullying victimization is important to intervene and protect children effectively in the school setting. The findings imply that parental involvement influenced by a cultural context, school resources, and children's attachment to their schools need to be acknowledged in studying peer bullying victimization.

\section{AUTHOR BIOGRAPHIES}

Note: Both authors contributed equally to the study.

Gang Lee is an associate professor of Criminal Justice at the Kennesaw State University. He received his Ph.D. in Sociology/Criminology in 1998 from the University of Florida. His current research is a comparative study of juvenile delinquency that employs theoretical frameworks into historically and culturally different societies in order to broaden our understanding of different approaches to youth problems. He also researches crimes and deviant behaviors in the Internet and cyberspace. His recent publications have appeared in the Social Science Journal, Social Science Quarterly, Crime and Delinquency, and Western Criminology Review. Email: glee18@kennesaw.edu. Contact author.

Yanghee Kim is an associate professor at the Department of Elementary and Early Childhood Education in Kennesaw State University. She received her Ph.D. in Curriculum and Instruction from the University of Maryland, College Park. Her main research interests focus on the creation of school environment that facilitates the engagement of families, especially minority families, in their children's learning. She published her articles with Childhood Education, Early Child Development and Care, Educational Research Review, Health Care for Woman International, and Teaching and Teacher Education. Email: ykim44@kennesaw.edu (contact author)

\section{REFERENCES}

Antonopoulou, K., Koutrouba, K., and Bablis, T. (2011). Parental involvement in secondary education schools: The views of parents in Greece. Educational Studies, 37: 333-344

Bronfenbrenner, U. (1986). Ecology of the family as a context for human development: Research perspectives. Developmental Psychology, 22, 723-742.

Card, N. A., \& Hodges, E. V. E. (2008). Peer victimization among schoolchildren: Correlations, causes, consequences, and considerations in assessment and intervention. School Psychology Quarterly, 23, 451-461.

Costigan, C. L., \& Koryzma, C. M. (2011). Acculturation and adjustment among immigrant Chinese parents: Mediating role of parenting efficacy. Journal of Counseling Psychology, 58, 183-196.

DeVoe, J., Peter, K., Kaufman, P., Miller, A., Noonan, M., Snyder, T. \& Baum, K. (2004). Indicators of school crime and safety: 2004. Washington D.C.: U.S. Department of Education.

Foy, P., Arora, A., \& Stanco, G. M. (2013). TIMSS 2011 User guide for the international database. International Association for the Evaluation of Educational Achievement (IEA). Chestnut Hill, MA: TIMSS \& PIRLS International Study Center. from http://english.moe.go.kr/web/1691/site/contents/en/en_0203.jsp

Georgiou, S. N. (2008). Bullying and victimization at school: The role of mothers. British Journal of Educational Psychology, $78,109-125$.

Huang, H., Hong, J. S., \& Espelage, D. L. (2013). Understanding factors associated with bullying and peer victimization in Chinese schools within ecological contexts. Journal of Child and Family Studies, 22, 881-892.

Indexmundi (2016). World factbook. Retrieved from http://www.indexmundi.com/factbook/countries

Japanese Ministry of Education, Culture, Sports, Science and Technology. (2015). Education. Retrieved from http://www.mext.go.jp/english/introduction/1303952.htm

Korean Ministry of Education (2015). Introduction: Education system overview. Retrieved

Lai, S-L., Ye, R., \& Chang, K-P. (2008). Bullying in middle schools: An Asian-pacific regional study. Asia Pacific Regional Review, 9, 503-515.

Lee, C., \& Song, J. (2012). Functions of parental involvement and effects of school climate on bullying behaviors among South Korean middles school students. Journal of Interpersonal Violence, 27, 2437-2464.

Lee, S., Turnbull, A. P., \& Zan, F. (2009). Family perspectives: Using a cultural prism to understand families from Asian cultural backgrounds. Intervention in School and Clinic, 45, 99-108. 
Malete, L. (2007). Aggressive and antisocial behaviors: Among secondary school students in Botswana. School Psychology International, 28, 90-109

Manyika, J., Sinclair, J., Dobbs, R., Strube, G., Rassey, L., Mischke, J., \& Ramaswamy, D. O. (2012). Manufacturing the future: The next era of global growth and innovation. Retrieved from National Institute of Standards and Technology website: http://www.nist.gov/mep/data/upload/Manufacturing-the-Future.pdf

Nakamoto, J., \& Schwartz, D. (2009). Is peer victimization associated with academic achievement? A meta-analytic review. Social Development, 19, 221-242.

Nansel, T. R., Overpeck, M., Pilla, R. S., Ruan, W. J., Simon-Morton, B., \& Scheidt, P. (2001). Bullying behaviors among US youth: Prevalence and association with psychosocial adjustment. The Journal of the American Medical Association, 285, 2094-2100. doi:10.1001/jama.285.16.2094

National Center for Education Statistics, Institute of Education Sciences. (2015). Digest of Education Statistics: Table 165 Age range for compulsory school attendance and special education services, and policies on year-round schools and kindergarten programs, by state: Selected years, 1997 through 2008. Retrieved from http://nces.ed.gov/programs/digest/d08/tables/dt08_165.asp

Peterson, P. E., Woessmann, L., Hanushek, E. A., \& Lastra-Ānadón, L. (2011, Fall). Are U.S. students ready to compete?: The latest on each state's international standing. EducationNext, 11(4), 50-59.

Raudenbush, S. W., \& Bryk, A. S. (2002). Hierarchical linear models: Applications and data analysis methods. Thousand Oaks, CA: Sage.

Smith, P. K. (2003). Violence in schools: The response in Europe. New York, NY: Routledge.

Taiwanese Ministry of Education (2015). Introduction: Educational System. Retrieved from http://english.moe.gov.tw/ct.asp?xItem $=15742 \&$ CtNode $=11434 \& \mathrm{mp}=1$

The World Bank. (2016). GDP per capita, PPP (current international \$). Retrieved from http://data.worldbank.org/indicator/NY.GDP.PCAP.PP.CD/countries

Welsch, W. (2000). The effects of school climate on school disorder. The Annals of the American Academy of Political and Social Science, 567: 88-107. 